\title{
POTENCIAL DA MEMBRANA AMNIÓTICA HUMANA NA ODONTOLOGIA
}

\section{Paula Cristina Santos Alves ${ }^{1}$ \\ Luciana Barros Sant'Anna²}

Resumo: A membrana amniótica (MA) humana tem sido utilizada como biomaterial para reconstruções cirúrgicas há quase 100 anos, e mais recentemente, para o tratamento de doenças inflamatórias e degenerativas, em diversas áreas incluindo dermatologia, cirurgia, e oftalmologia. Considerando o sucesso de sua aplicação nestas áreas e as propriedades pró-regenerativas da MA, acredita-se que ela tenha potencial terapêutico, também na odontologia. Neste contexto, o objetivo do trabalho foi realizar uma revisão integrativa da literatura sobre, a estrutura e propriedades da membrana amniótica, formas de uso e suas aplicações terapêuticas na odontologia. Observou-se que graças às propriedades anti-inflamatória, antifibrótica, antimicrobiana, de reepitelização, biocompatibilidade, permeabilidade e flexibilidade, a MA, especificamente na forma intacta e criopreservada, tem sido utilizada em reconstruções periodontais, envolvendo defeitos de furca e recessões gengivais, em vestibuloplastias, e correção de defeitos da mucosa oral, causados por lesões pré-cancerígenas e recessões tumorais.

Palavras-chave: Membrana amniótica; Odontologia; Propriedades; Estrutura; Preservação.

\footnotetext{
1 Odontologia - Universidade do Vale do Paraíba - UNIVAP, Av. Shishima Hifumi, 2911 - São José dos Campos, SP, Brasil, 12244-000. E-mail: paulaalves.odontologia@gmail.com.

2 Odontologia - Universidade do Vale do Paraíba - UNIVAP, Av. Shishima Hifumi, 2911 - São José dos Campos, SP, Brasil, 12244-000. E-mail: lucianabsa@gmail.com.
} 